\title{
Is Perineural Invasion a Novel Prognostic Factor Useful to Tailor Adjuvant Treatment in Patients Treated With Primary Surgery for Cervical and Vulvar Carcinoma?
}

\author{
ANGIOLO GADDUCCI ${ }^{1}$, SABINA PISTOLESI ${ }^{2}$, STEFANIA COSIO $^{1}$ and ANTONIO GIUSEPPE NACCARATO ${ }^{2}$ \\ ${ }^{1}$ Department of Experimental and Clinical Medicine, \\ Division of Gynecology and Obstetrics, University of Pisa, Pisa, Italy; \\ ${ }^{2}$ Department of New Technologies and Translational Research, Division of Pathology, University of Pisa, Pisa, Italy
}

\begin{abstract}
Perineural invasion (PNI) is detected in 7.0-35.1\% of cervical carcinomas. This histological finding correlates with cervical invasion, lymph-vascular space invasion (LVSI), tumor size, positive resection margins, parametrial invasion, node metastases and advanced stage. Some authors have reported that PNI has no prognostic relevance, others have found that PNI is related to disease-free survival or overall survival (OS) at univariate analysis, and others have observed that it is an independent poor prognostic factor for OS. The evaluation of PNI status should be included in the decisionmaking process for planning adjuvant treatment. PNI has been found in 7.6-52.4\% of vulvar carcinomas. This feature, which is strongly associated with depth of invasion, LVSI, tumor size, advanced stage and nodal involvement, is an independent prognostic variable for the risk of recurrence and death in most series. PNI should be evaluated routinely in histopathology reports of vulvar carcinoma and could help clinicians to tailor adjuvant treatment.
\end{abstract}

Perineural invasion (PNI) is usually defined as the presence of tumor cells within any of the three layers of the nerve sheath (endoneurium, perineurium and epineurium) or as the presence of tumor in close proximity to a nerve and involving at least one-third of the nerve's circumference (1).

This article is freely accessible online.

Correspondence to: Angiolo Gadducci, MD, Department of Clinical and Experimental Medicine, Division of Gynecology and Obstetrics, University of Pisa, Via Roma 56, Pisa, 56127, Italy. E-mail: a.gadducci@med.unipi.it

Key Words: Perineural invasion, cervical cancer, vulvar cancer, surgery, adjuvant therapy, review.
An immuno-histochemical staining using the S100 antibody for nerve tissue or a double immunostaining using this antibody and an antibody against cytokeratin AE1/3 for epithelial cells can be useful for the pathologist (2-7).

From a histopathological point of view, the definition of PNI can be referred to the presence of tumor cells "in, around and through the nerve" (8). In the histopathological reports two types of PNI are generally described: the invasion of perineurium (Figures 1 and 2) and the invasion of endoneurium (Figures 3). The latter is less frequent because the epineurium is resistant to invasion. However, both of types can be observed together (Figure 4).

PNI which expresses the potential of the tumor to infilter nervous structures and to spread along nerve sheaths, is detectable in several malignancies, such as cutaneous squamous cell carcinoma (9), prostate cancer (10), pancreatic cancer (11), ampullary cancer (12), gastric cancer (13), colon cancer $(12,14)$ and head and neck cancer $(2,15,16)$. This feature correlates with a high risk of loco-regional relapse and unfavorable clinical outcome.

The present paper reviews the literature data on the prognostic relevance of PNI in cervical and vulvar carcinoma.

\section{Carcinoma of the Uterine Cervix}

PNI has been detected in 7.0-35.1\% of patients with cervical cancer who underwent radical hysterectomy and pelvic lymphadenectomy $(5,17-23)$ (Table I). This histological finding significantly correlates with deep cervical invasion $(5$, 17, 18, 23-26), lymph-vascular space invasion (LVSI) (5, 19, $20,23,26)$, large tumor size $(5,19,23,25,26)$, tumor extension to the uterus $(19,24)$, positive resection margins (26), parametrial invasion $(19,20,22,23,26)$, lymph node metastases $(5,17,23,26)$, and more advanced stage $(5,17$ 19, 25, 26). Meinel et al. (18) found that PNI was also 


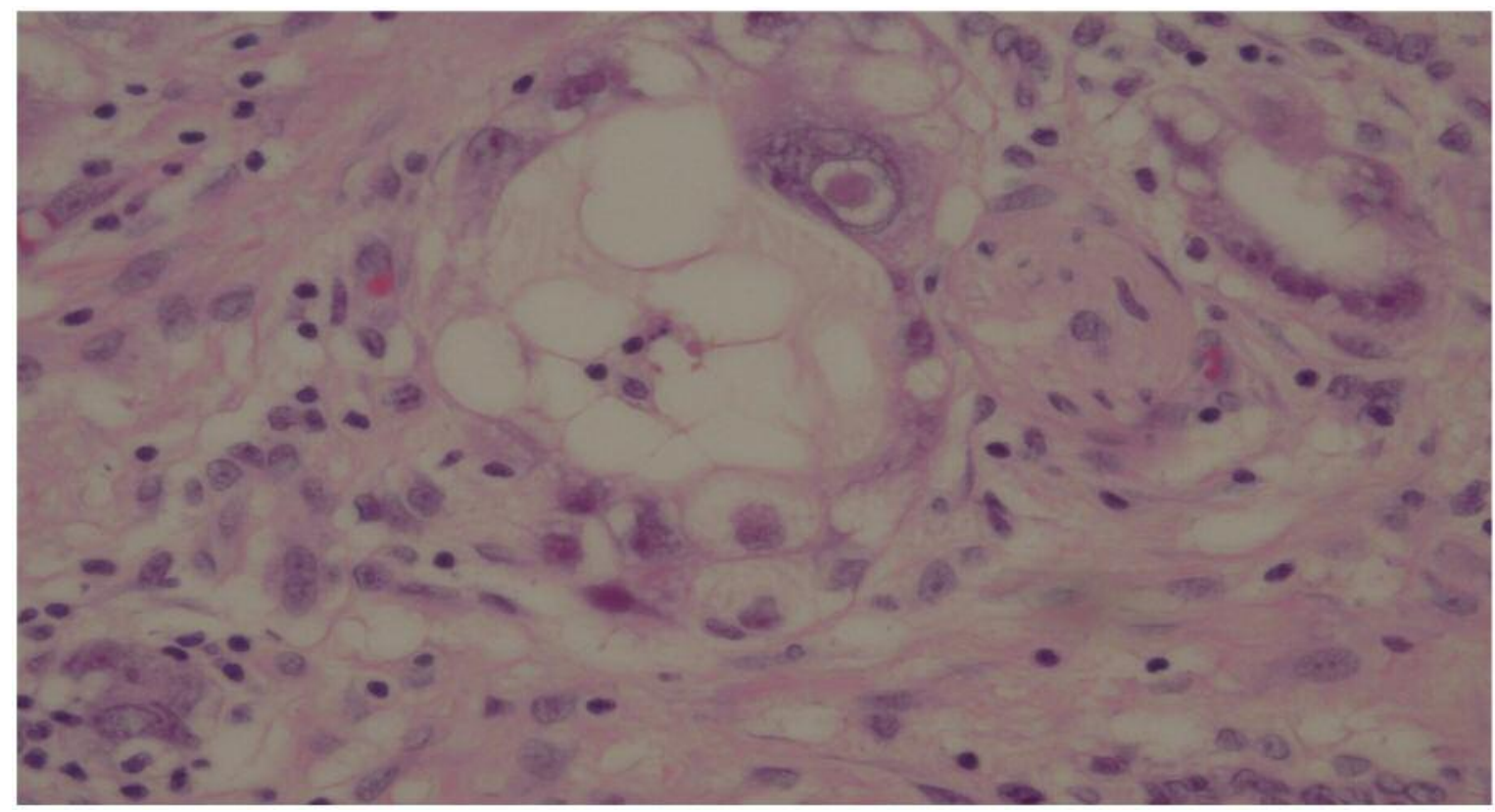

Figure 1. Cervical clear cell carcinoma: invasion of perineurium (HE, 20x).

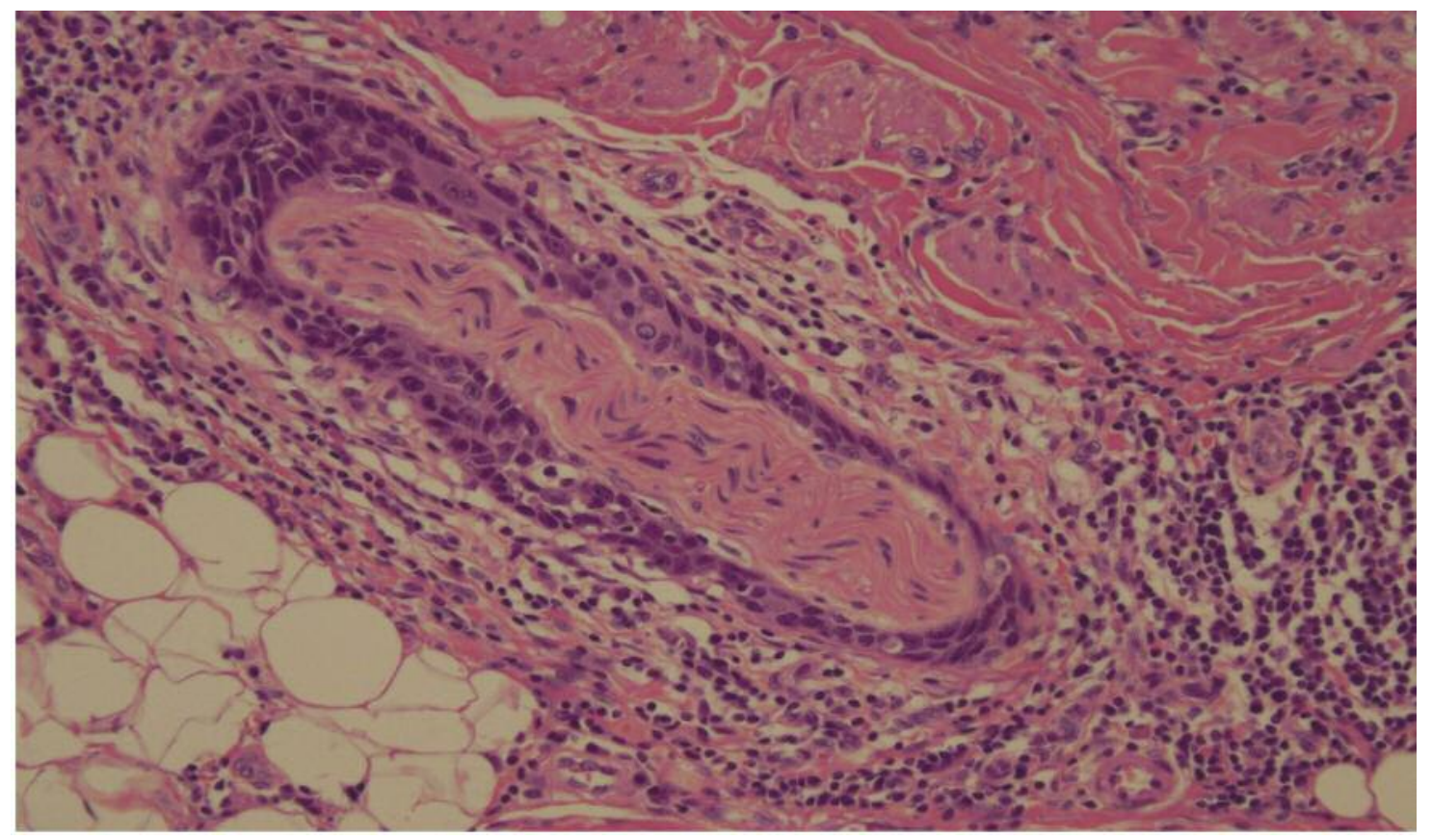

Figure 2. Vulvar squamous cell carcinoma: circumferential invasion of the perineurium; neoplastic cells occupy the space located between the nerve axons and the epineural fibrous sheath (HE, 10X).

associated with high grade of tumor cell dissociation (i.e., spray-like rather than finger-like or pushing pattern of invasion), strong peritumoral desmoplastic stromal reaction, and reduced peritumoral inflammation. A study on surgical samples of 312 patients with FIGO stage I-IIB cervical adenocarcinoma treated with radical surgery noted that PNI was significantly related to the risk of ovarian metastases at univariate but not at multivariate analysis (21). Patients with 


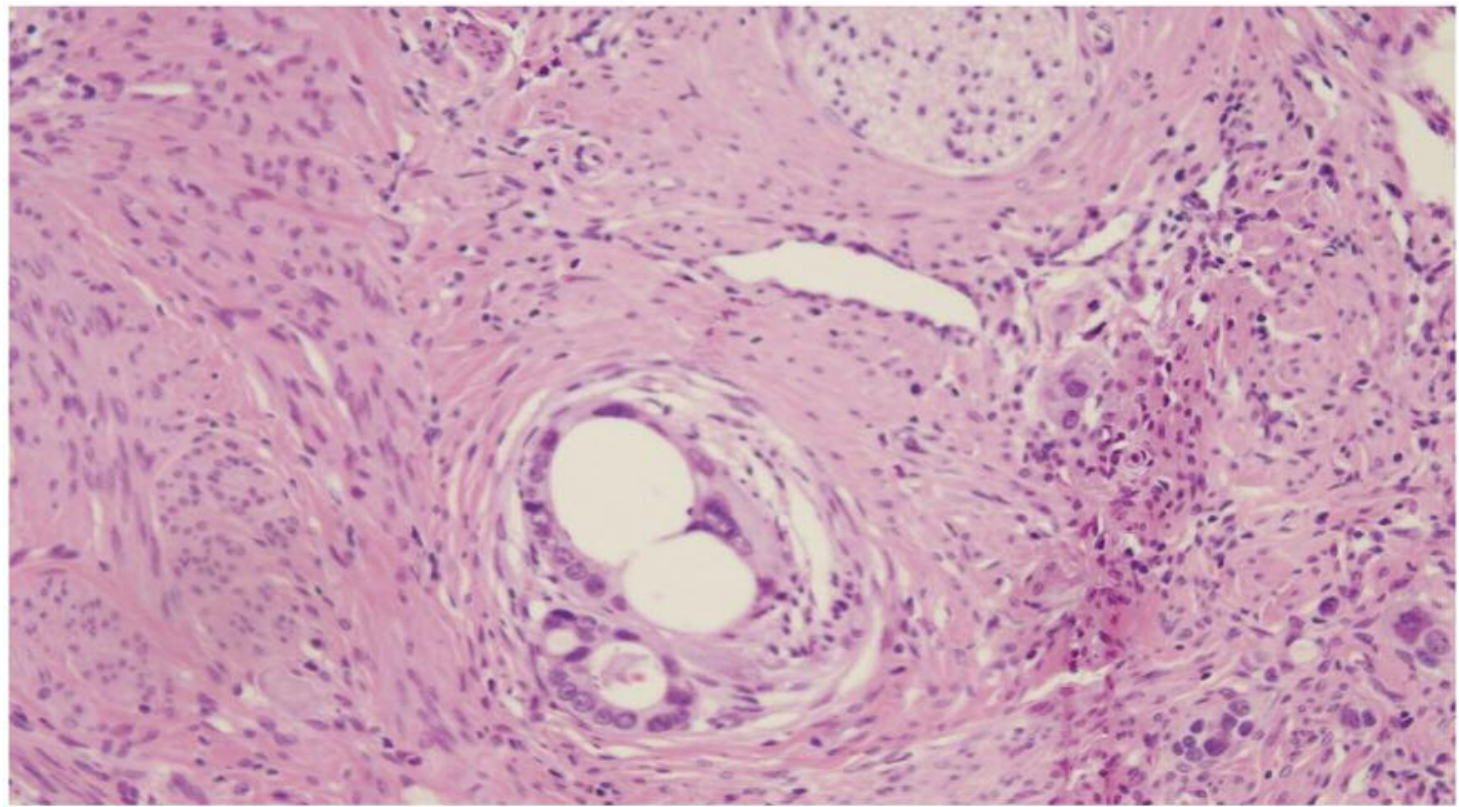

Figure 3. Cervical clear cell carcinoma: invasion of endoneurium; the axon blundles are almost completely replaced by neoplastic glands (HE, 10X).

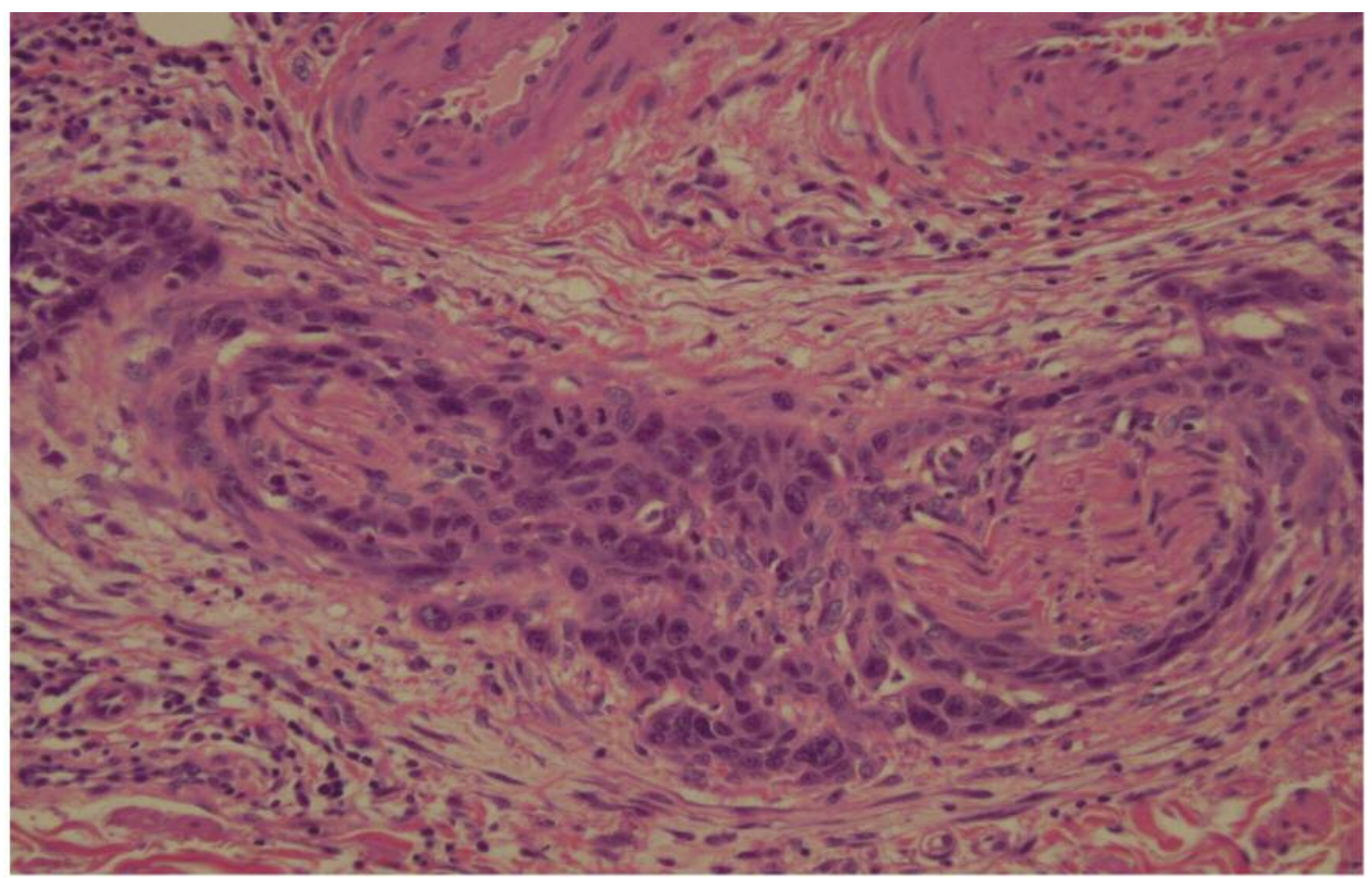

Figure 4. Vulvar squamous cell carcinoma: invasion of perineurium and endoneurium (on the left) (HE, 10x).

PNI had a higher chance to receive adjuvant radiotherapy or concurrent chemoradiation after surgery $(5,19,20,23,27)$.

Nerve growth factor (NGF) may stimulate PNI through the interaction with the transmembrane tropomyosin-receptor kinase receptor (Trk-A) which triggers signaling pathways involving PI3-Akt-mTOR and Ras-MAP and activates neuronal growth and survival (28). Conversely, NGF binding to transmembrane p75 neurotrophin receptor (p75NRT) 
Table I. Incidence of perineural invasion in cervical carcinoma.

\begin{tabular}{|c|c|c|c|}
\hline Authors (ref.) & $\begin{array}{l}\text { FIGO } \\
\text { stage }\end{array}$ & $\begin{array}{l}\text { Patients } \\
\text { (n) }\end{array}$ & $\begin{array}{c}\text { Perineural } \\
\text { invasion }\end{array}$ \\
\hline Wei et al. (5) & Ib1-IIb* & 206 & $16.0 \%$ \\
\hline Horn et al. (17) & $\mathrm{Ib}-\mathrm{IIb}^{* *}$ & 194 & $35.1 \%$ \\
\hline Meinel et al. (18) & $\mathrm{Ib} 1-\mathrm{IIb}^{* *}$ & 194 & $35.1 \%$ \\
\hline Elsahwi et al. (19) & Ia-II* & 192 & $12.5 \%$ \\
\hline Cho et al. (20) & $\mathrm{Ia}_{2}-\mathrm{IIa}_{2} *$ & 185 & $7.0 \%$ \\
\hline Zhou et al. (21) & $\mathrm{Ia}-\mathrm{IIb}^{*} * *$ & 312 & $13.1 \%$ \\
\hline Baiocchi et al. (22) & $\mathrm{Ia}_{2}-\mathrm{Ib}_{2} *$ & 345 & $17.9 \%$ \\
\hline Zhu et al. (23) & $\mathrm{Ia}_{2}-\mathrm{IIa}_{2} *$ & 210 & $8.6 \%$ \\
\hline
\end{tabular}

*Squamous cell carcinoma, adeno/adenosquamous carcinoma; **squamous cell carcinoma; ***adenocarcinoma.

might enhance pro-apoptotic signaling through pathways involving nuclear factor-B and c-Jun N-terminal kinase (29). Long et al. (28) found that the expression of NGF and TrkA, but not that of p75NRT, were strongly associated with PNI in 85 patients with FIGO stage Ib-IIb squamous cell carcinoma or adenocarcinoma of the uterine cervix treated with radical hysterectomy and pelvic lymphadenectomy. Moreover, a high expression of NGF and TrKA significantly correlated with worse disease-free survival (DFS) and worse overall survival (OS).

Although PNI is often associated with unfavorable prognosis, its real impact on the clinical outcome of surgicallytreated patients with cervical carcinoma is still debated. Some authors reported that PNI has no prognostic relevance $(19,20$, 25,30 ), whereas others found that PNI is related to DFS or OS at univariate but not at multivariate analysis $(23,26,31)$, and others observed that it is an independent poor prognostic factor for OS $(17,27)$ (Table II).

Cho et al. (20) failed to detect any significant difference in either DFS or OS according to the presence of PNI in 185 patients with stage $\mathrm{Ia}_{2}-\mathrm{IIa}_{2}$ disease, Elzawi et al. (19) reported no difference in either DFS or OS by PNI status in 192 patients with stage Ia-IIa disease, Skręt-Magierło et al. (25) found that PNI was not related to DFS in 50 patients with stage Ib1-IIb disease, and Tavares et al. (30) noted that PNI did not influence OS in a series of 301 patients.

A retrospective Indian study on 111 patients reported a lower 5-year OS for the patients with PNI compared with those without PNI (80.9\% versus $95.3 \%, p=0.022)$, but this variable was not an independent prognostic factor (26). Fiveyear DFS was not significantly different according to PNI. A subsequent assessment performed by grouping patients on the basis of stage (early stage, $\leq \mathrm{II}$, versus advanced stage, $\geq \mathrm{IIb}$ ) and nodal status, showed that the 5-year OS was $42.6 \%$ for advanced stage patients with PNI compared to $58.0 \%$ for those in advanced stage without PNI ( $p=0.047)$, and that the 5-year OS was $35.5 \%$ for patients with node metastases and PNI
Table II. Prognostic relevance of perineural invasion in cervical carcinoma.

\begin{tabular}{|c|c|c|}
\hline $\begin{array}{l}\text { No prognostic } \\
\text { relevance }\end{array}$ & $\begin{array}{c}\text { Prognostic relevance } \\
\text { at univariate } \\
\text { analysis }\end{array}$ & $\begin{array}{c}\text { Prognostic relevance } \\
\text { at multivariate } \\
\text { analysis }\end{array}$ \\
\hline Elzawi et al. (19) & Vural et al. (26) & Horn et al. (17) \\
\hline Cho et al. (20) & Zhu et al. (23) & Cui et al. (27)* \\
\hline Skręt-Magierło et al. (25) & Known et al. (31) & \\
\hline Tavares et al. (30) & & \\
\hline
\end{tabular}

compared to $60.1 \%$ for those with node metastases without PNI $(p=0.039)$. Although PNI was not an independent prognostic factor, this variable seemed to have a relevant impact on OS of patients with advanced stage and/or positive nodes.

In a series of 210 patients with FIGO stage $\mathrm{Ia}_{2}$-IIa cervical carcinoma, PNI was significantly related to DFS [hazard ratio $(\mathrm{HR})=3.56,95 \%$ confidence Interval $(\mathrm{CI})=1.53-8.29$, $p=0.009]$ and $\mathrm{OS}(\mathrm{HR}=2.98,95 \% \mathrm{CI}=0.84-10.86, p=0.049)$ at univariate but not at multivariate analysis (23).

A retrospective investigation on 50 high-risk, FIGO stage $\mathrm{Ia}_{2}$-IIb cervical carcinoma patients who underwent radical surgery followed by adjuvant radiation or concurrent chemoradiation reported a 5-year DFS of $38.1 \%$ for the patients with PNI versus $82.2 \%$ for those without PNI $(p=0.012)$ (31). Again, this variable was not an independent prognostic factor. Moreover, the 5-year OS was not significantly different in the two groups $(83.3 \%$ versus $87.0 \%, p=0.801$ ).

Conversely, Horn et al. (17), who reassessed 194 surgically-treated patients with cervical carcinoma, noted that the 5-year OS was $51.1 \%$ for the patients with PNI versus $75.6 \%$ for those without PNI $(p=0.001)$ and that this difference retained statistical significance at multivariate analysis.

A meta-analysis of retrospective observational studies with survival analysis for PNI after radical hysterectomy and lymphadenectomy demonstrated that patients with PNI had a trend to a worse DFS ( $\mathrm{HR}=1.35,95 \% \mathrm{CI}=0.78-2.31$, $p=0.28)$ and a significant worse $\mathrm{OS}(\mathrm{HR}=2.21,95 \% \mathrm{CI}=1.36$ $3.59, p=0.001)(27)$.

Two large retrospective studies, which assessed patients treated with pelvic exenteration for gynecological cancers, mostly consisting of cervical cancers, showed that PNI was a significant poor predictive factor for the risk of recurrence, for the risk of death and for the risk of death from cancer at univariate but not at multivariate analysis $(32,33)$. 
Table III. Incidence of perineural invasion in squamous cell vulvar carcinoma.

\begin{tabular}{lccc}
\hline $\begin{array}{l}\text { Authors } \\
\text { (ref.) }\end{array}$ & $\begin{array}{c}\text { FIGO } \\
\text { stage }\end{array}$ & $\begin{array}{c}\text { Patients } \\
\text { (n) }\end{array}$ & $\begin{array}{c}\text { Perineural } \\
\text { invasion }\end{array}$ \\
\hline $\begin{array}{l}\text { Lerma et al. (34) } \\
\text { Holthoff et al. (4) }\end{array}$ & I-IV & 71 & $21.4 \%$ \\
Salcedo et al. (35) & I-IV & $103^{\mathrm{a}}$ & $52.4 \%$ \\
Long et al. (6) & I-IV & 421 & $7.6 \%$ \\
Ferrari et al. (7) & I-IV & 105 & $28.6 \%$ \\
\hline
\end{tabular}

aNine patients had recurrent tumor.

\section{Carcinoma of the Vulva}

PNI has been found in 7.6-52.4\% of patients with squamous cell carcinoma of the vulva $(4,6,7,34,35)$ (Table III). Most papers reported that this feature significantly correlates with depth of invasion $(4,6)$, LVSI $(6,35)$, large tumor size $(6)$, more advanced stage (35) and nodal involvement $(6,35,36)$.

In a retrospective review of 421 patients treated at the Memorial Anderson Cancer Center between 1993 and 2011, the patients with PNI were more likely to have LVSI $(53.1 \%$ versus $15.9 \%, p<0.001)$, stage III-IV disease $(59.4 \%$ versus $36.0 \%, p=0.007)$, positive lymph nodes $(50.0 \%$ versus $21.6 \% p=0.002)$ than those without PNI (35). PNI was also associated with a higher incidence of lichen sclerosus $(25.0 \%$ versus $15.4 \%, p=0.024)$, whereas no significant differences in age, race/ethnicity, smoking history, histologic subtype, or grade were detected according to PNI status.

In a Chinese study, PNI was associated with the risk of recurrence at univariate $(\mathrm{HR}=2.93,95 \% \mathrm{CI}=1.20-7.37$, $p=0.018)$ but not at multivariate analysis $(\mathrm{HR}=1.63$, 95\% CI $=0.79-3.37, p=0.187$ ) (6) (Table IV). In the study of Lerma et al (34) including 71 cases of invasive squamous cell carcinoma of the vulva, PNI was significantly related to $\mathrm{OS}$ at univariate analysis. In the retrospective investigation of the University of Arkansas, PNI was present in 21 of the 31 primary tumors that recurred (69\%) versus 27 of the $63(42 \%)$ that did not $(p=0.0290)$, and this feature was found to be an independent predictor of failure $(\mathrm{OR}=2.613,95 \% \mathrm{CI}$ not available, $p=0.045)$ (4).

In the series of the Memorial Anderson Cancer Center, the patients with PNI had worse PFS (median=17.5 months versus 29.0 months, $p=0.004$ ) and worse OS (median, 25.5 months versus 94.3 months $(p<0.001)$ than those without $\mathrm{PNI}$, and this finding retained statistical significance at multivariate analysis for both DFS (HR=1.64, $p=0.020)$ and OS $(\mathrm{HR}=2.71, p<0.001)(35)$. An Italian study reported that the 5-year DFS and 5-year OS were significantly shorter for patients with PNI compared to those without PNI (18\% versus $72 \%, p=0.001$, and, respectively, $35 \%$ versus $75 \%$,
Table IV. Prognostic relevance of perineural invasion in squamous cell vulvar carcinoma.

\begin{tabular}{ll}
\hline $\begin{array}{l}\text { Prognostic relevance } \\
\text { at univariate analysis }\end{array}$ & $\begin{array}{l}\text { Prognostic relevance } \\
\text { at multivariate analysis }\end{array}$ \\
\hline Long et al. (6) & Holthoff et al. (4) \\
Lerma et al. (34) & Salcedo et al. (35) \\
& Ferrari et al. (7) \\
\hline
\end{tabular}

$p=0.001)(7)$. PNI was an independent prognostic variable for both DFS $(\mathrm{HR}=2.74,95 \% \mathrm{CI}=1.10-7.13, p=0.03)$ and $\mathrm{OS}$ $(\mathrm{HR}=4.93,95 \% \mathrm{CI}=1.33-18.35, p=0.01)(7)$.

\section{Conclusion}

PNI correlates with a high risk of loco-regional relapse and unfavorable clinical outcome in several malignancies (2, 916, 37). For instance, in a series of 363 patients with Dukes' $\mathrm{B}$ or $\mathrm{C}$ stage rectal cancer who did not undergo chemoradiotherapy, patients with PNI-positive disease had a significantly higher recurrence rate compared to those with PNI-negative disease $(p<0.001)$, which suggested that PNI status in primary rectal cancer specimens should be taken into consideration for therapy stratification (37).

As far as gynecological cancer is concerned, PNI status significantly correlates with several poor prognostic pathological variables of cervical carcinoma, but its relevance as independent predictor of either DFS or OS is still debated. The extensive use of adjuvant radiotherapy or concurrent chemoradiation after surgery in patients with PNI is probably due to the frequent coexistence of other unfavorable prognostic variables on surgical specimens, such as deep cervical invasion, LVSI, large tumor size, positive resection margins, parametrial invasion and lymph node involvement (18-20, 22-26). Nevertheless, the evaluation of PNI status should be included in the decision-making process for the planning of postoperative adjuvant treatment in patients with cervical carcinoma (27).

The few available data on vulvar carcinoma agree that the presence of PNI is suggestive of an aggressive biological behavior and show that this histologic finding is an independent prognostic variable for the risk of recurrence and death in most series $(4,7,35)$.

According to both the European Society of Gynecological Oncology (ESGO) and the US NCCN clinical guidelines for the management of vulvar carcinoma, adjuvant inguinal and pelvic radiotherapy is warranted after radical vulvectomy and full inguino-femoral lymphadenectomy in patients with more than one intranodal metastasis or with extra-nodal tumor growth (38, 39). Personalized adjuvant irradiation is indicated also for patients with positive surgical margins not amenable of re- 
excision. Data from recent literature seem to suggest that PNI should be evaluated routinely and included in histopathology reports of carcinoma of the vulva, and that combining PNI with other prognostic risk factors could help the clinicians to tailor postoperative adjuvant treatment $(4,6,7)$. A study conducted at Massachusetts General Hospital or Brigham and Women's Hospital in Boston on 114 primary cutaneous squamous cell carcinomas with PNI showed that tumors involving unnamed nerves of caliber $<0.1 \mathrm{~mm}$ without other risk factors usually had a good prognosis (9). Conversely, large-caliber nerve invasion was associated with an elevated risk of lymph node metastasis and death, which might be due in part to the multiple other risk factors associated. The prognostic relevance of the diameter of the nerves involved by squamous cell carcinoma of the vulva should be accurately assessed in future clinical trials.

\section{Conflicts of Interest}

The Authors declare no conflicts of interest regarding this study.

\section{Authors' Contributions}

Conceptualization, Writing - original draft: Angiolo Gadducci; Data curation, Formal analysis, Methodology, Writing- review \& editing: Angiolo Gadducci, Sabina Pistolesi, Stefania Cosio, Antonio Giuseppe Naccarato.

\section{References}

1 Liebig C, Ayala G, Wilks JA, Berger DH and Albo D: Perineural invasion in cancer: a review of the literature. Cancer 115: 33793391, 2009. PMID: 19484787. DOI: 10.1002/cncr.24396

2 Kurtz KA, Hoffman HT, Zimmerman MB and Robinson RA: Perineural and vascular invasion in oral cavity squamous carcinoma: increased incidence on re-review of slides and by using immunohistochemical enhancement. Arch Pathol Lab Med 129: 354-3519, 2005. PMID: 15737030. DOI: 10.1043/15432165(2005) 129<354:PAVIIO>2.0.CO;2

3 Shimada Y, Kido T, Kameyama H, Nakano M, Yagi R, Tajima Y, Okamura T, Nakano M, Nagahashi M, Kobayashi $T$, Minagawa M, Kosugi S, Wakai T and Ajioka Y: Clinical significance of perineural invasion diagnosed by immunohistochemistry with anti-S100 antibody in Stage I-III colorectal cancer. Surg Today 45: 1493-1500, 2015. PMID: 25502403. DOI: 10.1007/s00595-014-1096-9

4 Holthoff ER, Jeffus SK, Gehlot A, Stone R, Erickson SW, Kelly T, Quick CM and Post SR: Perineural invasion is an independent pathologic indicator of recurrence in vulvar squamous cell carcinoma. Am J Surg Pathol 39: 1070-1074, 2015. PMID: 25786085. DOI: $10.1097 /$ PAS.0000000000000422

5 Wei YS, Yao DS and Long Y: Evaluation of the association between perineural invasion and clinical and histopathological features of cervical cancer. Mol Clin Oncol 5: 307-311, 2016. PMID: 27588197. DOI: 10.3892/mco.2016.941

6 Long Y, Yao DS, Wei YS, Wei CH and Chen XY: Prognostic significance of perineural invasion in vulvar squamous cell carcinoma. Cancer Manag Res 11: 4461-4469, 2019. PMID: 31191008. DOI: 10.2147/CMAR.S198047
7 Ferrari F, Forte S, Ardighieri L, Bonetti E, Fernando B, Sartori $\mathrm{E}$ and Odicino F: Multivariate analysis of prognostic factors in primary squamous cell vulvar cancer: The role of perineural invasion in recurrence and survival. Eur J Surg Oncol 45: 21152119, 2019. PMID: 31378417. DOI: 10.1016/j.ejso.2019.07.029

8 Batsakis JG: Nerves and neurotropic carcinomas. Ann Otol Rhinol Laryngol 94: 426-427, 1985. PMID: 4026129.

9 Carter JB, Johnson MM, Chua TL, Karia PS and Schmults CD: Outcomes of primary cutaneous squamous cell carcinoma with perineural invasion: an 11-year cohort study. JAMA Dermatol 149: 35-41, 2013. PMID: 23324754. DOI 10.1001/jamadermatol.2013.746

10 Lubig S, Thiesler T, Müller S, Vorreuther R, Leipner N and Kristiansen G: Quantitative perineural invasion is a prognostic marker in prostate cancer. Pathology 50: 298-304, 2018. PMID: 29448999. DOI: 10.1016/j.pathol.2017.09.013

11 Furuhashi S, Sakaguchi T, Murakami T, Fukushima M4, Morita Y, Ikegami K, Kikuchi H, Setou M and Takeuchi H: Tenascin C in the tumor-nerve microenvironment enhances perineural invasion and correlates with locoregional recurrence in pancreatic ductal adenocarcinoma. Pancreas 49: 442-454, 2020. PMID: 32132519. DOI: 10.1097/MPA.0000000000001506.

12 Moekotte AL, Lof S, Van Roessel S, Fontana M, Dreyer S, Shablak A, Casciani F, Mavroeidis VK, Robinson S, Khalil K, Gradinariu G, Mowbray N, Al-Sarireh B, Fusai GK, Roberts K, White S, Soonawalla Z, Jamieson NB and Salvia R: Histopathologic predictors of survival and recurrence in resected ampullary adenocarcinoma: international multicenter cohort study. Ann Surg, 2019. DOI: 10.1097/SLA.0000000000003177

13 Zhao B, Lv W, Mei D, Luo R, Bao S, Huang B and Lin J: Perineural invasion as a predictive factor for survival outcome in gastric cancer patients: a systematic review and meta-analysis. J Clin Pathol, 2020. DOI: 10.1136/jclinpath-2019-206372

14 Kim S, Huh J, Lee WY, Yun SH, Kim HC, Cho YB, Park YA and Shin JK: Lymphovascular invasion, perineural invasion, and tumor budding are prognostic factors for stage I colon cancer recurrence. Int J Colorectal Dis 35: 881-885, 2020. PMID: 32112198. DOI: $10.1007 / \mathrm{s} 00384-020-03548-4$

15 Zhu J, Zhou R, Wang Y and Yu M: Perineural invasion as a prognostic factor in head and neck squamous cell carcinoma: a systematic review and meta-analysis. Acta Otolarynol 139: 1038-1043, 2019. PMID: 31464544. DOI: 10.1080/0001 6489.2019.1655167

16 Park J, Megow A, Swalling A, Hodge JC, Foreman A, Boase S, Valentine R, Krishnan S and Ooi EH: Prognosis of oral squamous cell carcinoma with perineural invasion: a comparative study of classification types. Clin Otolaryngol 45: 99-105, 2020. PMID: 31677332. DOI: 10.1111/coa.13472

17 Horn LC, Meinel A, Fischer U, Bilek K and Hentschel B: Perineural invasion in carcinoma of the cervix uteri--prognostic impact. J Cancer Res Clin Oncol 136: 1557-1562, 2010. PMID: 20169362. DOI: 10.1007/s00432-010-0813-Z

18 Meinel A, Fischer U, Bilek K, Hentschel B and Horn LC: Morphological parameters associated with perineural invasion (PNI) in carcinoma of the cervix uteri. Int J Surg Pathol 19: 159163, 2011. PMID: 21087982. DOI: 10.1177/1066896910381898

19 Elsahwi KS, Barber E, Illuzzi J, Buza N, Ratner E, Silasi DA, Santin AD, Azodi M, Schwartz PE and Rutherford TJ: The significance of perineural invasion in early-stage cervical cancer. Gynecol Oncol 123: 561-564, 2011. PMID: 21968340. DOI: 10.1016/j.ygyno.2011.08.028 
20 Cho HC, Kim H, Cho HY, Kim K, No JH and Kim YB: Prognostic significance of perineural invasion in cervical cancer. Int J Gynecol Pathol 32: 228-233, 2013. PMID: 23370644. DOI: 10.1097/PGP.0b013e318257df5f

21 Zhou J, Chen Y, Zhang P and Lou H: Ovarian preservation in adenocarcinoma of the uterine cervix. J Ovarian Res 10: 48 2017. PMID: 28738842. DOI: 10.1186/s13048-017-0339-y

22 Baiocchi G, de Brot L, Faloppa CC, Mantoan H, Duque MR3, Badiglian-Filho L, da Costa AABA and Kumagai LY: Is parametrectomy always necessary in early-stage cervical cancer? Gynecol Oncol 146: 16-19, 2017. PMID: 28392128. DOI: 10.1016/j.ygyno.2017.03.514

23 Zhu Y, Zhang G, Yang Y, Cui L, Jia S, Shi Y, Song S and Xu S: Perineural invasion in early-stage cervical cancer and its relevance following surgery. Oncol Lett 15: 6555-6561, 2018. PMID: 29755594. DOI: 10.3892/ol.2018.8116

24 Ozan H, Ozuysal S and Ediz B: Perineural invasion in earlystage cervical carcinoma. Eur J Gynaecol Oncol 30: 379-383, 2009. PMID: 19761126.

25 Skręt-Magierło JE, Soja PJ, Skręt A, Kruczek A, Kaznowska E and Wicherek I: Perineural space invasion in cervical cancer (FIGO IB1-IIB) accompanied by high-risk factors for recurrence. J Cancer Res Ther 10: 957-961, 2014. PMID: 25579536. DOI: $10.4103 / 0973-1482.138126$

26 Vural C, Bayrak BY, Muezzınoglu B and Yucesoy I: Perineural invasion is a valuable prognostic factor in advanced stage and/or node $(+)$ cervical cancer. Indian J Pathol Microbiol 60: 27-32, 2017. PMID: 28195087. DOI: 10.4103/0377-4929.200021

27 Cui L, Shi Y and Zhang GN: Perineural invasion as a prognostic factor for cervical cancer: a systematic review and meta-analysis. Arch Gynecol Obstet 292: 13-19, 2015. PMID: 30246726. DOI: 10.1007/s00404-015-3627-Z

28 Long Y, Yao DS, Wei YS and Wu G: Effects of nerve growth factor expression on perineural invasion and worse prognosis in early-stage cervical cancer. Chin Med J (Engl) 131: 2360-2363, 2018. PMID: 24212627. DOI: 10.4103/0366-6999.241808

29 Molloy NH, Read DE and Gorman AM: Nerve growth factor in cancer cell death and survival. Cancers (Basel) 3: 510-530, 2011. PMID: 19820876 . DOI: 10.3390/cancers3010510

30 Tavares MB, Sousa RB, Oliveira e Silva T, Moreira LA, Silva LT, Tavares CB and Vieira SC: Prevalence of prognostic factors for cancer of the uterine cervix after radical hysterectomy. Sao Paulo Med J 127: 145-149, 2009. PMID: 26194370. DOI: 10.1590/s1516-31802009000300007

31 Kwon J, Eom KY, Kim IA, Kim JS, Kim YB, No JH and Kim $\mathrm{K}$ : Prognostic value of log odds of positive lymph nodes after radical surgery followed by adjuvant treatment in high-risk cervical cancer. Cancer Res Treat 48: 632-640, 2016. PMID: 25637504. DOI: $10.4143 /$ crt.2015.085

32 Baiocchi G, Guimaraes GC, Rosa Oliveira RA, Kumagai LY, Faloppa CC, Aguiar S, Begnami MD, Soares FA and Lopes A: Prognostic factors in pelvic exenteration for gynecological malignancies. Eur J Surg Oncol 38: 948-954, 2012. PMID: 22818842. DOI: $10.1016 /$ j.ejso.2012.07.002
33 Westin SN, Rallapalli V, Fellman B, Urbauer DL, Pal N, Frumovitz MM, Ramondetta LM, Bodurka DC, Ramirez PT and Soliman PT: Overall survival after pelvic exenteration for gynecologic malignancy. Gynecol Oncol 134: 546-551, 2014. PMID: 25014540. DOI: 10.1016/j.ygyno.2014.06.034

34 Lerma E, Matias-Guiu X, Lee SJ and Prat J: Squamous cell carcinoma of the vulva: study of ploidy, HPV, p53, and pRb. Int J Gynecol Pathol 18: 191-197, 1999. PMID: 1209058. DOI: 10.1097/00004347-199907000-00001

35 Salcedo MP, Sood AK, Dos Reis R, Ramalingam P, Chen C, Frumovitz M, Jhingran A, Pitcher B, Ramirez PT and Schmeler KM: Perineural invasion (PNI) in vulvar carcinoma: a review of 421 cases. Gynecol Oncol 152: 101-105, 2019. PMID: 30396690. DOI: 10.1016/j.ygyno.2018.10.035

36 Rowley KC, Gallion HH, Donaldson ES, van Nagell JR, Higgins RV, Powell DE, Kryscio RJ and Pavlik EJ: Prognostic factors in early vulvar cancer. Gynecol Oncol 31: 43-49, 1988. PMID: 3410354. DOI: 10.1016/0090-8258(88)90267-3

37 Kinugasa T, Mizobe T, Shiraiwa S, Akagi Y and Shirouzu K: Perineural invasion is a prognostic factor and treatment indicator in patients with rectal cancer undergoing curative surgery: 20002011. Data from a single-center study. Anticancer Res 37: 39613968, 2017. PMID: 28668901. DOI: 10.21873/anticanres.11780

38 Oonk MHM, Planchamp F, Baldwin P, Bidzinski M, Brännström M, Landoni F Mahner S, Mahantshetty U, Mirza M, Petersen C, Querleu D, Regauer S, Rob L, Rouzier R, Ulrikh E, van der Velden J, Vergote I, Woelber L and van der Zee AGJ: European Society of Gynaecological Oncology guidelines for the management of patients with vulvar cancer. Int J Gynecol Cancer 27: 832-837, 2017. PMID: 28441255 . DOI: $10.1097 / \mathrm{IGC} .0000000000000975$

39 Koh WJ, Greer BE, Abu-Rustum NR, Campos SM, Cho KR, Chon HS, Chu C, Cohn D, Crispens MA, Dizon DS, Dorigo O, Eifel PJ, Fisher CM, Frederick P, Gaffney DK, Han E, Higgins S, Huh WK, Lurain $3^{\text {rd } J R, ~ M a r i a n i ~ A, ~ M u t c h ~ D, ~ N a g e l ~ C, ~}$ Nekhlyudov L, Fader AN, Remmenga SW, Reynolds RK, Tillmanns T, Ueda S, Valea FA, Wyse E, Yashar CM, McMillian N and Scavone J: Vulvar cancer, version 1.2017, NCCN Clinical Practice Guidelines in Oncology. J Natl Compr Canc Netw 15: 92-120, 2017. PMID: 28040721. DOI: 10.6004/jncen.2017.0008

Received April 22, 2020

Revised May 4, 2020

Accepted May 6, 2020 